\section{Communicating Higher Education: An Analysis of Journals in the Field of Higher Education}

\section{Ariane de Gayardon}

Ariane de Gayardon is a graduate assistant at the Center for International Higher Education at Boston College. E-mail: ariane. de.gayardon@gmail.com.

$\mathrm{I}$ $\mathrm{n}$ the year 2013-20I4, the Center for International High1 er Education conducted an exhaustive project to gather information about higher education research and training around the world (Higher Education: A Worldwide Inventory of Research Centers, Academic Programs, and Journals and Publications by Laura E. Rumbley, Philip G. Altbach, David Stanfield, Yukiko Shimmi, Ariane de Gayardon, and Roy Y. Chan). It includes a list of 280 journals and publications, primarily concerning higher education. This inventory provides a basis for highlighting trends in the higher education publishing sector, as well as identifying necessary development to ensure equal sharing of knowledge in the field. It is also a useful guide to the trends in research and analysis in the rapidly expanding field of higher education studies in the 2 Ist century.

\section{Data Collection}

The work on this project began with a list of publication titles generated by the Center for International Higher Education in 2006. This list was updated and substantially expanded with the help of national and regional experts. Further information on the titles-including country, focus, language(s), frequency, publisher, and Web site-was mostly obtained from the journal Web sites. When such data collection was impossible due to language barriers or the absence of a Web site, the help of experts from the country of publication was sought again.

Some compromises had to be made as we proceeded with the data collection and redefined the project. In China, we chose, with the assistance of Chinese experts, to include slightly fewer than 30 journals circulated nationally, excluding publications that are mainly distributed at the local university level. Additionally, in countries that did not have journals specific to higher education, we opted to include a few publications with a broader focus but that constitutes a reliable source for higher education researchers.

The large majority of the publications included in the inventory publish research and analysis on higher educa- tion. Newspapers and magazines concerning higher education also appear as they are of great importance to the field. Some of the publications included are only available in electronic version, but we limited ourselves to actual publication or news Web sites, thus excluding some electronic resources that publish analysis or comments on higher education.

\section{KeY Findings}

The inventory provides information on 280 journals written in 22 different languages and published in 35 countries. The English language dominates with Igo journals. Twenty of these journals are multilingual-being published in English and at least one other language. Other major languages of publication include Chinese (27 journals), Japanese (26), Spanish (15), French (8), and German (7).

The countries of publication are dominated by the United States with Ior journals (36\%), and the United Kingdom (ז2\%). These two Anglophone countries are followed by Japan, China, Canada, and Australia. The clear domination of the United States could be due to choices made to limit the number of publications from some countries, but more certainly stems from the long history of higher education as an academic discipline in the United States and the strength of its publishing sector.

Most journals in higher education seem to be targeted to a domestic audience, thus emphasizing the diversity of national systems. However, we found that 53 journals/ publications (I9\%) have an international focus. Somewhat fewer publications are aimed at a regional audience: 3 in Africa, 2 in Asia, 7 in Europe, 5 in Latin America, and I in the Middle East and North Africa region.

For more than 80 percent of the publications, we were able to provide information that explains the main focus of the journals. Unsurprisingly, one quarter of the journals in the inventory are very generally focused and claim to publish all types of research and analysis on higher education. The rest are extremely varied, and only a few focuses are shared by more than io journals in the world. The most prevalent focus area is that of teaching and learning: 27 publications cite it as one of their main focuses. Policy, reform, and changes are also at the heart of conversation, with i8 journals making these topics their priority. The third most common focus areas are management, organization, and governance, as well as student affairs-the latter mostly thanks to the dominance of this topic in the United States (I3 journals out of 15 ). Other focus areas worth noting in terms of prevalence include continuing and adult education; internationalization, globalization, and cross-border education; and distance education. The rest of the publications indicate a main focus on areas ranging from evaluation or quality to specific student populations-such as 
African American or Hispanic.

\section{What Did We LEARn?}

The publication landscape is dominated by the Englishspeaking world, as evidenced by the languages and the countries of publication. This is worrying, as most of the research therefore follows the orientations of a small subset of the global population, emphasizing characteristics of a higher education system that might not be valid for all. More importantly, this domination prevents knowledge from spreading in remote places where English language is seldom used or where publications are not available. Efforts have to be made to disseminate research in higher education more widely, by encouraging open source publications as well as appropriate translations.

\section{It includes a list of 280 journals and publications, primarily concerning high- er education.}

The number of publications also show that a few countries are clearly leading the higher education research landscape- the United States, the United Kingdom, China, and Japan. In many countries around the world, higher education has not emerged as an important area for academic inquiry, and many countries are lacking the appropriate and reliable knowledge that can inform policymaking. Regionally, Latin America, Africa, Middle East and North Africa are highly underrepresented, as well as Asia, except for China and Japan. Efforts should be made to help researchers in these regions and enhance regional collaboration to strengthen the knowledge base in higher education.

The regional distribution of publications in the field of higher education also parallels the National Science Foundation's 2009 estimate of global research and development expenditures. North America and Asia are the leading research and development investors, the latter being heavily driven by China and Japan, while regions like Africa and the Middle East lag behind. Unsurprisingly, this suggests that the availability of funds is correlated with the output of research in higher education, as in other fields.

Finally, the range of publication focus areas reflects well the diversity of higher education stakeholders around the world. It is encouraging to see that so many issues are rising to the attention of researchers and the public, showing the complexity of the higher education field. This emphasizes the need to prioritize issues at the policy level.
The absence of any publication emphasizing the funding of higher education as a main focus struck us as unique, especially when considering the importance of the issue today for students, parents, institutions, and policymakers. However, there is no lack of research on this subject, and we can only assume that publications with a broader focus publish extensively on the subject of funding and finance. Overall, the aim of publications with specific focus areas might be to drive interest on an underresearched topic, thus leaving prominent issues to the broadly focused publications.

\section{CONCLUSION}

The higher education publication sector is quite uneven worldwide, as some countries can count on numerous publications with diverse focuses, while others do not even enjoy a single publication focused solely on higher education. The need to make sure that knowledge is shared more equally around the world is pressing, an effort that should be undertaken by researchers, publishers, and policymakers

Note: Higher Education: A Worldwide Inventory of Research Centers, Academic Programs, and Journals and Publications is published by Lemmens Media. It is available under three formats: an e-book, a downloadable PDF, or a printed book.

\section{International Higher Educa- tion Research and Compara- tive Analysis}

\section{Anna Kosmützky and Georg Krücken}

Anna Kosmützky is a researcher and Georg Krücken is director of the International Center for Higher Education Research, University of Kassel, Germany. E-mail: kosmuetzky@incher.uni-kassel.de.E-mail: kruecken@incher-kassel.de.

Tnternational comparative higher education research has 1 been a popular and valuable field of research. International and global trends and developments in higher education have stimulated higher education research on a worldwide scale in recent years. Simultaneously, international higher education research has increased in volume and even more in popularity. Furthermore, international collaboration in research in general has intensified and proliferated rapidly in the last two decades. This trend has also been en- 